\title{
APLICAÇÃO DE GLIFOSATO EM PÓS-EMERGÊNCIA, EM SOJA TRANSGÊNICA CULTIVADA NO CERRADO
}

\author{
Luiz Lonardoni Foloni ${ }^{1}$, Domingos Rodrigues ${ }^{2}$, Fabiano Ferreira ${ }^{3}$, Ricardo Miranda ${ }^{4}$, \\ Elizabeth Orika Ono ${ }^{5}$
}

${ }^{1}$ Eng $^{\mathrm{o}}$ Agr $^{\mathrm{o}}$, Prof. Dr. Colaborador, Departamento de Água no Solo, Faculdade de Engenharia Agrícola, Universidade Estadual de Campinas, UNICAPM, Campinas, SP.

${ }^{2}$ Eng $^{\mathrm{o}}$ Agr $^{\mathrm{O}}$, Prof. Titular, Departamento de Botânica, Instituto de Biociências, Campus de Botucatu, Universidade Estadual Paulista, UNESP, 18618-000, Botucatu, SP, fone (14) 6802-6053, fax (14) 6821-3744

${ }^{3} \mathrm{Eng}^{\mathrm{o}} \mathrm{Agr}^{\mathrm{O}}$ Departamento de Produção e Desenvolvimento, Monsanto do Brasil, Rondonópolis, MT.

${ }_{5}^{4}$ Eng $^{\mathrm{o}}$ Agr $^{\mathrm{o}}$ Departamento de Produção e Desenvolvimento, Monsanto do Brasil, São Paulo, SP.

5 Prof $^{\mathrm{a}}$ Adjunta/Livre-docente, Departamento de Botânica, Instituto de Biociências, Campus de Botucatu, Universidade Estadual Paulista, UNESP, 18618-000, Botucatu, SP, fone (14) 6802-6053, fax (14) 68213744

\section{RESUMO}

O experimento foi instalado na cultura de soja transgênica (Glycine max (L.) Merrill) da variedade Soy 8888-RR plantada em 11 de janeiro de 1999. Antes da semeadura foi realizada uma aplicação de glifosato a $1,2 \mathrm{~kg} / \mathrm{L}$ e sete dias após esse manejo foi efetuada a semeadura em sistema de plantio direto. Os produtos foram aplicados em área total da parcela, empregando equipamento de precisão a gás carbônico $\left(\mathrm{CO}_{2}\right)$. Os tratamentos empregados foram: glifosato a 0,48;0,72;0,96;1,20 e 1,44 kg/ha aos 31 dias após a emergência (DAE); glifosato a $0,72 \mathrm{~kg} / \mathrm{ha}$ aos 22 DAE e $0,48 \mathrm{~kg} / \mathrm{ha}$ aos $42 \mathrm{DAE}$; glifosato a $0,96 \mathrm{~kg} / \mathrm{ha}$ aos $22 \mathrm{DAE}$ e $0,72 \mathrm{~kg} / \mathrm{ha}$ aos $42 \mathrm{DAE}$; chlorimuron-ethyl + lactofen a $0,01+$ $0,072 \mathrm{~kg} / \mathrm{ha}$, respectivamente, aos 31 DAE e testemunha com capina e sem capina. Os parâmetros avaliados foram fitotoxicação aparente aos 15, 20, 42 e 51 dias após a aplicação dos tratamentos (DAA), altura das plantas e eficácia agronômica aos 20 e 51 DAA e produção de grãos. Através dos resultados obtidos pode-se observar que glifosato na formulação utilizada, independentemente da concentração empregada, apresentou efeito de fitotoxicação aparente muito leve nas plantas de soja e em uma única ou duas aplicações sequienciais, mostrou-se eficazes no controle das plantas daninhas presentes.

Palavras-chave: fitotoxicação, glifosato, plantas transgênicas

\section{POST-EMERGENCE APPLICATION OF GLYPHOSATE ON TRANSGENIC SOYBEAN GROWN IN THE CERRADO ABSTRACT}

The experiment was installed on a transgenic soybean field (Glycine max (L.) Merrill), variety Soy 8888-RR, planted on January 11, 1999. One glyphosate application at $1.2 \mathrm{~kg} / \mathrm{L}$ was performed before seeding, which was carried out seven days after that management practice, in the no-till system. The products were applied in the entire area of the plot, using a carbon dioxide $\left(\mathrm{CO}_{2}\right)$ precision sprayer. Treatments consisted of: glyphosate at $0.48 ; 0.72 ; 0.96 ; 1.20$ and $1.44 \mathrm{~kg} / \mathrm{ha}$, applied 31 days after emergence (DAE); glyphosate at $0.72 \mathrm{~kg} / \mathrm{ha} 22 \mathrm{DAE}$ and at $0.48 \mathrm{~kg} / \mathrm{ha}$ applied $42 \mathrm{DAE}$; glyphosate at $0.96 \mathrm{~kg} / \mathrm{ha}$ applied $22 \mathrm{DAE}$ and at $0.72 \mathrm{~kg} / \mathrm{ha}$ applied $42 \mathrm{DAE}$; chlorimuron-ethyl + lactofen at $0.01+0,072 \mathrm{~kg} / \mathrm{ha}$, respectively, applied $31 \mathrm{DAE}$, plus hand-weeded and unweeded controls. The evaluated parameters consisted of apparent phytotoxicity at 15, 20, 
42 and 51 days after treatment application (DAA), plant height and agronomic efficiency at 20 and 51 DAA, and grain yield. From the results obtained, it can be seen that glyphosate at the employed formulation, regardless of the concentration used, showed a very slight apparent phytotoxicity effect on the soybean plants, and was efficient in controlling the existing weeds with a single or with two sequential applications.

Key-words: glyphosate, phytotoxicity, transgenic plants

\section{INTRODUÇÃOO}

O fato do código genético ser o mesmo em todos os seres vivos permite que um gene, parte do DNA que codifica uma proteína, possa ser retirado de um organismo e inserido no DNA de outro e venha a funcionar como se estivesse no organismo original. $O$ organismo que recebeu o gene "estranho" é o que chamamos de transgênico. Um dos primeiros organismos transgênicos úteis ao homem foi o de uma bactéria que recebeu o gene humano para a produção de insulina.

Parece fácil a obtenção de um organismo transgênico; seria apenas isolar o gene desejado e introduzi-lo no organismo que se quer transformar. A natureza tem mecanismos que impedem que informações genéticas de um organismo passe a outro com facilidade. Assim, na natureza, a transferência de material genético se dá com facilidade apenas verticalmente, isto é, de uma geração a outra, dentro da mesma espécie. Troca de material genético entre indivíduos, mesmo dentro de uma mesma espécie, é raríssimo na natureza (Paiva, 1999).

Uma vez obtida a planta transgênica com a característica desejada, o que só pode ser efetuado em laboratório e casa de vegetação devidamente licenciados, é necessário que a mesma seja avaliada em campo. Passada a fase de testes, entra-se na etapa de uso comercial (Paiva, 1999).

O glifosato, ([N-fosfonometil]glicina) é um herbicida que bloqueia a biossíntese de aminoácidos aromáticos, inibindo a atividade da 5-enol-piruvil-chiquimato-3-fosfato sintase - EPSPS (Kishore et al., 1992).

A soja transgênica (RR), geneticamente modificada com um gene que codifica a enzima EPSPS torna-se tolerante a ação do glifosato. Isso significa que a soja RR continua produzindo compostos essenciais ao seu desenvolvimento, seu crescimento não sendo afetado pelos efeitos do herbicida (Padgetlete et al., 1996; Bradshaw et al., 1997). Ralston \& Witt (1997) comentam que houve um rápido crescimento das plantas de soja transgênica tolerante ao glifosato desde sua introdução em 1996 no mercado americano.

O presente experimento procurou avaliar a formulação de glifosato - Mon 77280 aplicado em diferentes doses, isoladas ou seqüenciais na pós-emergência, sobre o cultivar de soja transgênica, M Soy 8888 - RR, resistente ao glifosato em área de cerrado e o efeito deste produto no controle de plantas daninhas.

\section{MATERIAL E MÉTODOS}

O experimento foi conduzido em cultura de soja transgênica (Glycine max (L.) Merrill) cv Soy 8888-RR) na estação experimental da Monsanto localizada no município de Rondonópolis, MT, em solo classificado como Latossolo Vermelho Escuro álico, A moderado, textura argilosa (Embrapa, 1981), com 3,5\% de matéria orgânica e pH 6,3.

Antes da semeadura da soja foi realizada uma aplicação de glifosato a $1,2 \mathrm{~kg} / \mathrm{ha} \mathrm{e}$, sete dias após foi efetuada a semeadura (11/01/1999) desta, em sistema de plantio direto, a 
uma densidade de 13 sementes por metro linear e profundidade de 0,03 a $0,05 \mathrm{~m}$. O espaçamento utilizado foi de $0,45 \mathrm{~m}$ entre linhas e a adubação básica na semeadura foi de $400 \mathrm{~kg} / \mathrm{ha}$ de NPK da formulação 2.2.20. O delineamento experimental utilizado foi blocos ao acaso, com 10 tratamentos e 3 repetições, compreendendo cada parcela uma área de 3,0 $\mathrm{x} 8,0 \mathrm{~m}$.

Os tratamentos utilizados com suas respectivas concentrações e época de aplicação são apresentados na Tabela 1. O herbicida glifosato utilizado foi Roundup Ready (MON 77280 ) contendo $648 \mathrm{~g} / \mathrm{L}$ de sal de isopropilamino de [N(fosfonometil)]glicina-glifosato. Como padrão foi utilizada a mistura clorimuron-ethyl + lactofen na dose de 0,01 + $0,072 \mathrm{~kg} / \mathrm{L}$, respectivamente.

Tabela 1. Produtos utilizados no experimento com suas respectivas doses e épocas de aplicação (Rondonópolis, MT, 1999).

\begin{tabular}{l|c|c}
\hline Produtos & $\begin{array}{c}\text { Época de aplicação } \\
\text { (dias após a emergência - DAE) }\end{array}$ & $\begin{array}{c}\text { doses } \\
\text { (kg/ha) }\end{array}$ \\
\hline glifosato & 31 & 0,48 \\
\hline glifosato & 31 & 0,72 \\
\hline glifosato & 31 & 0,96 \\
\hline glifosato & 31 & 1,20 \\
\hline glifosato & 22 e 42 & 0,72 e 0,48 \\
\hline glifosato & 22 e 42 & 0,96 e 0,72 \\
\hline glifosato & 31 & $0,01+0,072$ \\
\hline chlorimuron-ethyl + lactofen & 31 & - \\
\hline testemunha capinada & - & - \\
\hline Testemunha não capinada & & \\
\hline
\end{tabular}

A aplicação foi realizada com equipamento de precisão a gás carbônico $\left(\mathrm{CO}_{2}\right)$, na pressão de $2,08 \mathrm{kgf} / \mathrm{cm}^{2}$, provido de barra compensada localizada a $0,50 \mathrm{~m}$ acima da superfície do solo, com quatro pontas de jato plano da série 110.05, espaçados entre si em $0,50 \mathrm{~m}$ e com vazão equivalente a $100 \mathrm{~L} / \mathrm{ha}$.

As condições ambientais por ocasião da aplicação dos herbicidas são apresentadas na Tabela 2.

As avaliações de fitotoxicação à cultura foram realizadas aos 15, 20, 42 e 51 dias após a aplicação dos tratamentos (DAA) nas linhas centrais do experimento, empregando a escala visual onde $0 \%=$ sem sintoma de fitotoxicação e $100 \%=$ morte total da planta (EWRC, 1964). 
As avaliações de eficácia agronômica foram efetuadas aos 20 e 51 DAA, empregando-se a escala percentual, onde $0 \%$ representa nenhum controle e $100 \%$, ao controle total das plantas daninhas comparados à testemunha sem capina (EWRC, 1964).

Aos 15, 20, 42 e 111 dias após a aplicação foi medida a altura da planta de soja, com o objetivo de avaliar, de forma indireta, qualquer efeito adverso de fitotoxicação induzida pelo uso dos produtos.

A colheita foi realizada manualmente aos 114 dias após a emergência, colhendo-se as 4 linhas centrais de cada parcela, desprezando-se $0,50 \mathrm{~m}$ iniciais e finais. Os dados de produção de grãos foi pesado e corrigido para 13\% de umidade. Os valores obtidos foram transformados em sacos de soja de $60 \mathrm{~kg} / \mathrm{ha}$.

Os resultados foram submetidos à análise de variância (teste F) e as médias comparadas pelo teste Tukey a $10 \%$ de probabilidade. Os dados de fitotoxicação e eficácia agronômica foram transformados em arco seno $\sqrt{ } \mathrm{x} / 100$.

Tabela 2. Condições ambientais verificadas por ocasião das aplicações dos tratamentos, aos 22, 31 e 42 dias após a emergência (DAE) das plântulas de soja (Rondonópolis, MT, 1999).

\begin{tabular}{l|c|c|c}
\hline Fatores ambientais & $22 \mathrm{DAE}$ & $31 \mathrm{DAE}$ & $42 \mathrm{DAE}$ \\
\hline Temperatura do ar & $27,0^{\circ} \mathrm{C}$ & $29,0^{\circ} \mathrm{C}$ & $27,0^{\circ} \mathrm{C}$ \\
Umidade relativa do ar & $78 \%$ & $59 \%$ & $68 \%$ \\
Velocidade do vento & $2 \mathrm{~km} / \mathrm{h}$ & $0 \mathrm{~km} / \mathrm{h}$ & $1 \mathrm{~km} / \mathrm{h}$ \\
Direção do vento & $\mathrm{N}$ & - & $\mathrm{N}$ \\
Nebulosidade & $90 \%$ & $0 \%$ & $0 \%$ \\
Temperatura do solo & $26,0^{\circ} \mathrm{C}$ & $28,0^{\circ} \mathrm{C}$ & $27,0^{\circ} \mathrm{C}$ \\
Umidade do solo & Seco & Úmido & Seco \\
Precipitação semana anterior & $6,4 \mathrm{~mm}$ & $7,0 \mathrm{~mm}$ & $12,8 \mathrm{~mm}$ \\
$1^{\text {a }}$ chuva após tratamento - intervalo & 0 dias & 3 dias & $0 \mathrm{dias}$ \\
$1^{\text {a }}$ chuva após tratamento - intensidade & $5,8 \mathrm{~mm}$ & $1,0 \mathrm{~mm}$ & $1,0 \mathrm{~mm}$ \\
Hora do início da aplicação & $7: 10 \mathrm{~h}$ & $9: 10 \mathrm{~h}$ & $8: 20 \mathrm{~h}$ \\
Hora do término da aplicação & $7: 20 \mathrm{~h}$ & $9: 40 \mathrm{~h}$ & $8: 30 \mathrm{~h}$ \\
\hline
\end{tabular}

\section{RESULTADOS E DISCUSSÃO}


As espécies daninhas presentes no momento da aplicação dos produtos, assim como suas densidades relativas, são apresentados na Tabela 3. Foi observado que as poáceas apresentavam de 2 a 3 perfilhos e as dicotiledôneas, exceto para Chamaesyce hirta, encontravam-se no estádio vegetativo apresentando de $2-8$ folhas. Chamaesyce hirta encontrava-se no estádio vegetativo e apresentava 10 folhas.

Em relação à fitotoxicação, foi observado que apenas aos 20 DAA ocorreu sintomas de fitotoxicação sendo este muito leve em todos os tratamentos com glifosato, mostrando ser a cultura altamente seletiva a este herbicida (Tabela 4). Nas avaliações realizadas aos 15 e 20 DAA observou-se fitotoxicação entre leve a moderada para o tratamento padrão (chlorimuron-ethyl + lactofen).

Aos 20 DAA, foi observado para todas as doses individuais de glifosato a partir de $0,72 \mathrm{~kg} / \mathrm{ha}$, controles igual ou superior a $90 \%$ de Panicum maximum (Tabela 5). A aplicação de $0,48 \mathrm{~kg} / \mathrm{ha}$ proporcionou controle de $81,3 \%$ sendo este inferior aos obtidos com as doses de 0,96 a 1,20kg/ha. Aos 51 DAA, todos os tratamentos com glifosato apresentaram controle total dessa planta daninha, no entanto, o padrão utilizado, chlorimuron-ethyl + lactofen apresentou baixo controle de P. maximum (Tabela 5).

Para Eleusine indica e Desmodium tortuosum aos 20 e 51 DAA, pode-se observar que todos os tratamentos com glifosato foram eficazes no controle. Entretanto, o padrão somente apresentou controle eficaz de E. indica aos 51 DAA, pois aos 20 DAA, este foi de apenas $37,5 \%$ (Tabela 5) e o mesmo padrão apresentou bom controle de D. tortuosum aos 20 e 51 DAA.

Tabela 3. Plantas daninhas presentes na área experimental seus estádios de desenvolvimento, número de plantas por $\mathrm{m}^{2}$ e número de folhas (f) ou perfilhos (p), por ocasião da aplicação (Rondonópolis, MT, 1999)

\begin{tabular}{|c|c|c|c|c|}
\hline Nome científico & Nome comum & Estádio & Plantas $/ \mathrm{m}^{2}$ & $\mathrm{n}^{\mathrm{o}}$ f ou $\mathrm{p}$ \\
\hline \multicolumn{5}{|l|}{ Poaceae } \\
\hline Eleusine indica (L.) Gaertn. & Capim pé de galinha & $\mathrm{P}$ & 23 & $2 \mathrm{p}$ \\
\hline Panicum maximum Jacq. & Capim colonião & $\mathrm{P}$ & 138 & 2 a $3 p$ \\
\hline Asteraceae & & & & \\
\hline Acanthospermum australe (Loef.) Kunt. & Carrapichinho & V & 5 & $6 \mathrm{f}$ \\
\hline $\begin{array}{l}\text { Tridax procumbens L. } \\
\text { Papilionoideae }\end{array}$ & Erva de touro & $\mathrm{V}$ & 22 & $4 \mathrm{f}$ \\
\hline $\begin{array}{l}\text { Desmodium tortuosum (Sw.) DC. } \\
\text { Euphorbiacae }\end{array}$ & Carrapicho beiço de boi & V & 45 & $4 \mathrm{f}$ \\
\hline Chamaesyce hirta (L.) Millsp. & Erva de Santa Luzia & V & 21 & $10 \mathrm{f}$ \\
\hline
\end{tabular}


Convolvulaceae

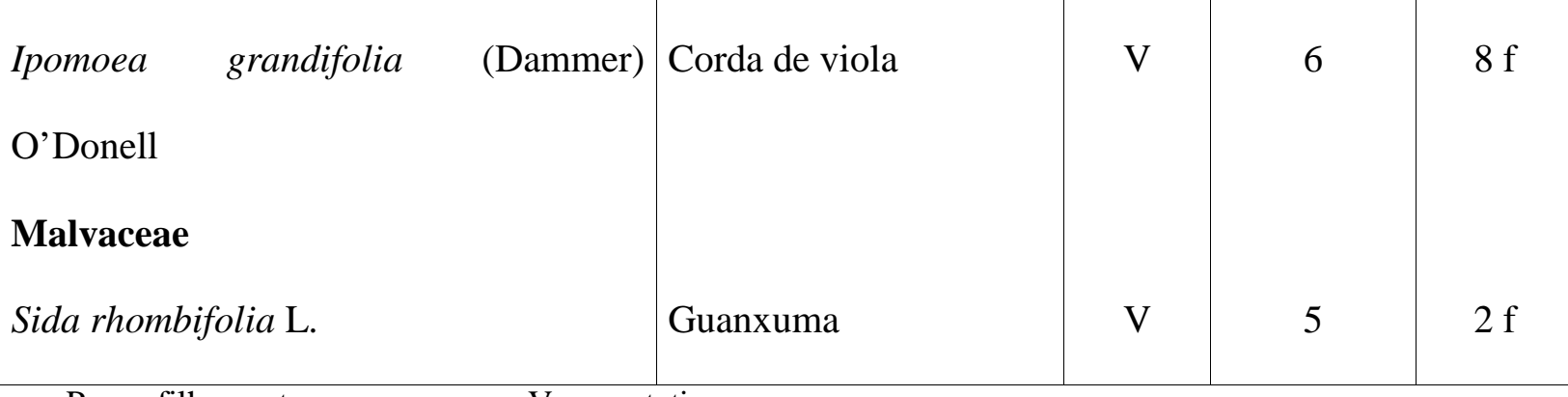

$\mathrm{P}=$ perfilhamento

$\mathrm{V}=$ vegetativo

Tridax procumbens, tanto aos 20 como aos 51 DAA foi susceptível à todos os herbicidas empregados (Tabela 6). Entretanto, foi observado que aos 20 e 51 DAA, a aplicação de $1,44 \mathrm{~kg} / \mathrm{ha}$ de glifosato proporcionou controle estatisticamente superior àquele obitdo quando foi aplicado 0,48 e $0,72 \mathrm{~kg} / \mathrm{ha}$.

Smith et al. (1998) estudando a aplicação de glifosato no controle de plantas daninhas em soja transgênica, observaram bom controle de Senna obtusifolia, Ipomoea lacunosa, Cyperus rotundus e Sida spinosa entre 75 a $85 \%$ e que o aumento da dose, ou aplicação tardia, não aumentava o nível de controle. Observaram ainda, que aplicações seqüenciais controlaram as plantas daninhas desde 85 a 95\%, e da mesma forma altas doses não melhoraram a eficiência, fato este não observado neste trabalho, uma vez que o controle das plantas daninhas com uma ou duas aplicações não foram significativamente mais eficientes.

Foloni et al. (1998) avaliando a seletividade e eficiência agronômica em três variedades de soja transgênica ao glifosato aplicado em pós-emergência, com concentrações de 0,48 a 1,704kg/ha observaram de bom a excelente controle de Pennisetum americanum, Ipomoea grandifolia, Euphorbia hirta, Acanthospermum australe e Emilia sonchifolia.

Não foi observado efeito de glifosato na produção. Houve diferença estatística apemas entre a testemunha não capinada e a dose de $0,48 \mathrm{~kg} / \mathrm{ha}$. O rendimento da cultura são apresentados na Tabela 8 . Pode-se observar que a maior produtividade $(4170 \mathrm{~kg} / \mathrm{ha})$ foi obtida com a menor concentração de glifosato empregada e a testemunha não capinada produziu 2010kg/ha. Os demais tratamentos apresentaram produção entre 2080 a $3540 \mathrm{~kg} / \mathrm{ha}$.

A altura das plantas de soja não foi afetada negativamente pelos tratamentos realizados aos 15 DAA. Já nas outras avaliações ocorreu diferença entre as plantas testemunha não capinada e os diferentes tratamentos herbicidas, os quais apresentaram sempre plantas mais baixas. Portanto, quanto à altura houve uma leve influência dos herbicidas aplicados à cultura da soja (Tabela 7).

Pode-se concluir que o glifosato, independentemente da concentração empregada apresentou efeito de fitotoxicação leve na cultura de soja. Chlorimuron-ethyl + lactofen apresentaram efeito de fitotoxicação entre leve a moderada à cultura de soja até aos 20 DA. A altura das plantas de soja foi influenciado pelos tratamentos herbicidas até aos 15 DAA, recuperando-se após esse período. O glifosato nas concentrações testadas, tanto numa única aplicação como em aplicações sequienciais, mostraram-se eficientes no controle das plantas daninhas presentes na área experimental. $O$ glifosato a $0,48 \mathrm{~kg} / \mathrm{ha}$ apresentou a maior produtividade de grãos com $4170 \mathrm{~kg} / \mathrm{h}$. Pode-se recomendar os herbicidas utilizados em 
pós-emergência em uma única aplicação ou em duas aplicações seqüenciais na cultura de soja transgênica variedade M Soy 8888 , no controle das plantas daninhas e pela segurança à cultura.

\section{LITERATURA CITADA}

BRADSHAW, L.D.; PADGETTE, S.R.; KIMBALL, S.L.; WELLS, B.H. Perspectives on glyphosate resistance. Weed Technol., v.11, p.189-190. 1997.

EMBRAPA. Serviço Nacional de Levantamento e Conservação de Solos. Mapa de Solos do Brasil, 1981.

KISHORE, G.M.; PADGETTE, S.R.; FRALEY, R.T. History of herbicide-tolerant crops, methods of development and current state of the art-emphasis on glyphosate tolerance. Weed Technol., v.6, p.626-634. 1992.

PADGETTE, S.R.; TAYLOR, N.B.; NIDA, D.L.; BAILEY, M.R.; MacDONALD, J.; HOLDEN, L.R.; FUCHS, R.L. The composition of glyphosate-tolerant soybean seeds is equivalent to that of conventional soybeans. Journal of Plant Nutrition, v.126, n.3, p.702716. 1996.

PAIVA, F.A. Sobre a soja transgênica. Plantio Direto, n.51, p.24-25. 1999.

RALSTON, J.L.; WITT, W.W. Movement of herbicides in shallow groundwater in no-till double-cropped soybean. In: KENTUCKY WATER RESOURCES ANNUAL SYMPOSIUM, Lexington, 1997. Proceedings. Lexington: KWRRI, 1997.

SMITH, M. C.; SHAW, D.R.; SHANKLE, M.W. 1998. Optimization of glyphosate rate and application timing for weed control in Mississippi glyphosate-tolerant soybean. Weed Sci. Soc. Am., v.38, p1-22, 1998.

SPRAYING SYSTEMS CO. Produtos de pulverização para a agricultura. Cat. 41M-P.S. Systems do Brasil, Diadema, 1990. 72p. 
Tabela 4. Estudo de doses de glifosato, aplicada em pós-emergência, em soja transgênica, aos 15, 20, 42 e 51 DAA (dias após a aplicação) empregando a escala visual. Rondonópolis, MT, 1998/99.

\begin{tabular}{|c|c|c|c|c|c|c|}
\hline \multirow[b]{2}{*}{ Produtos } & \multicolumn{2}{|c|}{ tratamentos } & \multicolumn{2}{|c|}{ Fitotoxicação } & \multicolumn{2}{|c|}{ (DAA) } \\
\hline & $\begin{array}{c}\text { Épocas } \\
\text { aplicação } \\
\text { (DAA) }\end{array}$ & $\begin{array}{c}\text { Dose } \\
\text { (kg/ha) }\end{array}$ & 15 & 20 & 42 & 51 \\
\hline Glifosato & 31 & 0,48 & $0 \mathrm{~b}$ & $0,0 \mathrm{c}$ & $0 \mathrm{a}$ & $0 \mathrm{a}$ \\
\hline Glifosato & 31 & 0,72 & $0 \mathrm{~b}$ & $1,3 \mathrm{bc}$ & $0 \mathrm{a}$ & $0 \mathrm{a}$ \\
\hline Glifosato & 31 & 0,96 & $0 \mathrm{~b}$ & $1,3 \mathrm{bc}$ & $0 \mathrm{a}$ & $0 \mathrm{a}$ \\
\hline Glifosato & 31 & 1,20 & $0 \mathrm{~b}$ & $2,5 \mathrm{bc}$ & $0 \mathrm{a}$ & $0 \mathrm{a}$ \\
\hline Glifosato & 31 & 1,44 & $0 \mathrm{~b}$ & $4,5 \mathrm{~b}$ & $0 \mathrm{a}$ & $0 \mathrm{a}$ \\
\hline Glifosato & 22 e 42 & 0,72 e 0,48 & $0 \mathrm{~b}$ & $1,3 \mathrm{bc}$ & $0 \mathrm{a}$ & $0 \mathrm{a}$ \\
\hline Glifosato & 22 e 42 & 0,96 e 0,72 & $0 \mathrm{~b}$ & $2,5 \mathrm{bc}$ & $0 \mathrm{a}$ & $0 \mathrm{a}$ \\
\hline Chlorimuron-ethyl + lactofen & 31 & $0,01+0,072$ & $20 \mathrm{a}$ & $26,3 \mathrm{a}$ & $0 \mathrm{a}$ & $0 \mathrm{a}$ \\
\hline Testemunha capinada & - & - & $0 \mathrm{~b}$ & $0,0 \mathrm{c}$ & $0 \mathrm{a}$ & $0 \mathrm{a}$ \\
\hline Testemunha & - & - & $0 \mathrm{~b}$ & $0,0 \mathrm{c}$ & $0 \mathrm{a}$ & $0 \mathrm{a}$ \\
\hline $\mathrm{F}$ tratamentos & & & $9,38 *$ & $4,06^{*}$ & - & - \\
\hline C.V. $(\%)$ & & & 4,28 & 1,85 & - & - \\
\hline
\end{tabular}


Tabela 5. Resultados médios de controle de Panicum maximum, Eleusine indica e Desmodium tortuosum aos 20 e 51 dias após a aplicação dos produtos (D.A.A.) pelo glifosato aplicado em pós-emergência na cultura de soja transgênica. Rondonópolis, MT, 1998/99.

\begin{tabular}{|c|c|c|c|c|c|c|c|}
\hline Produtos & Dose $(\mathrm{kg} / \mathrm{ha})$ & $\begin{array}{c}20 \\
\text { Panicum }\end{array}$ & $\begin{array}{c}51 \\
\text { maximum }\end{array}$ & $\begin{array}{c}20 \\
\text { Eleusine }\end{array}$ & $\begin{array}{r}51 \\
\text { indica }\end{array}$ & $\begin{array}{c}20 \\
\text { Desmodium }\end{array}$ & $\begin{array}{c}51 \\
\text { tortuosum }\end{array}$ \\
\hline Glifosato & 0,48 & $81,3 \mathrm{~b}$ & $100 \mathrm{a}$ & $88,8 \mathrm{~b}$ & $100 \mathrm{a}$ & $98,8 \mathrm{a}$ & $97,0 \mathrm{a}$ \\
\hline Glifosato & 0,72 & $90,0 \mathrm{ab}$ & $100 \mathrm{a}$ & $92,5 \mathrm{ab}$ & $99,5 \mathrm{a}$ & $100 \mathrm{a}$ & $100 \mathrm{a}$ \\
\hline Glifosato & 0,96 & 96,3 a & $100 \mathrm{a}$ & $96,3 \mathrm{ab}$ & $100 \mathrm{a}$ & $99,5 \mathrm{a}$ & $98,8 \mathrm{a}$ \\
\hline Glifosato & 1,20 & $96,5 \mathrm{a}$ & $100 \mathrm{a}$ & $95,8 \mathrm{ab}$ & $98,8 \mathrm{a}$ & $100 \mathrm{a}$ & $98,8 \mathrm{a}$ \\
\hline Glifosato & 1,44 & $98,8 \mathrm{a}$ & $100 \mathrm{a}$ & $99,0 \mathrm{ab}$ & $99,5 \mathrm{a}$ & $99,5 \mathrm{a}$ & $100 \mathrm{a}$ \\
\hline Glifosato & 0,72 e 0,48 & $88,8 \mathrm{ab}$ & $100 \mathrm{a}$ & $92,5 \mathrm{ab}$ & $100 \mathrm{a}$ & $100 \mathrm{a}$ & 99,0 a \\
\hline Glifosato & 0,96 e 0,72 & $94,5 \mathrm{a}$ & $100 \mathrm{a}$ & $91,3 \mathrm{ab}$ & $100 \mathrm{a}$ & $100 \mathrm{a}$ & 99,5 a \\
\hline $\begin{array}{l}\text { Chlorimuron-ethyl } \\
+ \text { lactofen }\end{array}$ & $0,01+0,072$ & $30,0 \mathrm{c}$ & $71,3 \mathrm{~b}$ & $37,5 \mathrm{c}$ & $97,5 \mathrm{a}$ & $90,0 \mathrm{~b}$ & $88,8 \mathrm{~b}$ \\
\hline $\begin{array}{l}\text { Testemunha } \\
\text { capinada }\end{array}$ & - & $100 \mathrm{a}$ & $100 \mathrm{a}$ & $100 \mathrm{ab}$ & $100 \mathrm{a}$ & $100 \mathrm{a}$ & $100 \mathrm{a}$ \\
\hline Testemunha & - & $0,0 \mathrm{~d}$ & $0,0 \mathrm{c}$ & $0,0 \mathrm{~d}$ & $0,0 \mathrm{~b}$ & $0,0 \mathrm{c}$ & $0,0 \mathrm{c}$ \\
\hline F tratamentos & & $11,3 *$ & $7,14 *$ & $9,81 *$ & $2,78^{*}$ & $2,04 *$ & $4,65^{*}$ \\
\hline C.V. (\%) & & 5,14 & 3,26 & 4,48 & 1,27 & 0,93 & 2,12 \\
\hline
\end{tabular}

Médias seguidas de mesma letra na coluna não diferem significativamente entre si pelo teste Tukey a $10 \%$ de probabilidade. 
Tabela 6. Resultados médios de controle de Tridax procumbens e Acanthospermum australe aos 20 e 51 dias após a aplicação dos produtos (D.A.A.), com glifosato em pós-emergência, na cultura de soja transgênica. Rondonópolis, MT, 1998/99.

\begin{tabular}{l|c|cc|cc}
\hline Produtos & $\begin{array}{c}\text { Dose } \\
\text { (kg/ha })\end{array}$ & \multicolumn{2}{c|}{$\begin{array}{c}20 \\
\text { Tridax }\end{array}$} & $\begin{array}{c}51 \\
\text { procumbens }\end{array}$ & $\begin{array}{c}\text { Acanthospermum } \\
\text { australe }\end{array}$ \\
\hline Glifosato & 0,48 & $80,0 \mathrm{c}$ & $92,5 \mathrm{~cd}$ & $98,8 \mathrm{a}$ & $98,8 \mathrm{a}$ \\
Glifosato & 0,72 & $82,5 \mathrm{c}$ & $90,0 \mathrm{~d}$ & $100 \mathrm{a}$ & $100 \mathrm{a}$ \\
Glifosato & 0,96 & $92,5 \mathrm{abc}$ & $93,3 \mathrm{bcd}$ & $100 \mathrm{a}$ & $100 \mathrm{a}$ \\
Glifosato & 1,20 & $90,0 \mathrm{abc}$ & $93,8 \mathrm{bcd}$ & $100 \mathrm{a}$ & $100 \mathrm{a}$ \\
Glifosato & 1,44 & $97,5 \mathrm{ab}$ & $98,8 \mathrm{ab}$ & $100 \mathrm{a}$ & $100 \mathrm{a}$ \\
Glifosato & $0,72 \mathrm{e} 0,48$ & $85,0 \mathrm{bc}$ & $96,3 \mathrm{abc}$ & $100 \mathrm{a}$ & $100 \mathrm{a}$ \\
Glifosato & $0,96 \mathrm{e} 0,72$ & $91,3 \mathrm{abc}$ & $98,3 \mathrm{ab}$ & $100 \mathrm{a}$ & $100 \mathrm{a}$ \\
Chlorimuron-ethyl & $0,01+0,072$ & $88,8 \mathrm{abc}$ & $94,5 \mathrm{ad}$ & $98,8 \mathrm{a}$ & $98,8 \mathrm{a}$ \\
lactofen & & & & & $100 \mathrm{a}$ \\
Testemunha capinada & - & $100 \mathrm{a}$ & $100 \mathrm{a}$ & $100 \mathrm{a}$ & $0,0 \mathrm{~b}$ \\
Testemunha & - & $0,0 \mathrm{~d}$ & $0,0 \mathrm{e}$ & $0,0 \mathrm{~b}$ & $2,49 *$ \\
\hline F tratamentos & & $13,5^{*}$ & $5,64^{*}$ & $2,31^{*}$ & 1,14 \\
C.V. (\%) & & 6,19 & 2,58 & 1,05 & \\
\hline
\end{tabular}

Médias seguidas de mesma letra na coluna não diferem significativamente entre si pelo teste Tukey a $10 \%$ de probabilidade. 
Tabela 7. Efeito de doses de glifosato, aplicada em pós-emergência, na altura de plantas de soja transgênica, aos 15, 20, 42 e 51 DAA (dias após a aplicação). Rondonópolis, MT, 1998/99.

\begin{tabular}{|c|c|c|c|c|c|c|}
\hline \multirow[b]{2}{*}{ Produtos } & \multicolumn{2}{|c|}{ tratamentos } & \multicolumn{4}{|c|}{ Fitotoxicação $\quad$ (DAA) } \\
\hline & $\begin{array}{c}\text { Épocas } \\
\text { aplicação } \\
\text { (DAA) }\end{array}$ & $\begin{array}{c}\text { Dose } \\
\text { (kg/ha) }\end{array}$ & 15 & 20 & 42 & 51 \\
\hline Glifosato & 31 & 0,48 & $34,3 \mathrm{a}$ & $36,5 \mathrm{ab}$ & $75,3 \mathrm{~b}$ & $71,3 \mathrm{ab}$ \\
\hline Glifosato & 31 & 0,72 & $33,3 \mathrm{a}$ & $35,3 \mathrm{~b}$ & $78,0 \mathrm{ab}$ & $64,3 \mathrm{~b}$ \\
\hline Glifosato & 31 & 0,96 & $31,5 \mathrm{a}$ & $39,8 \mathrm{ab}$ & $82,0 \mathrm{ab}$ & $68,0 \mathrm{ab}$ \\
\hline Glifosato & 31 & 1,20 & $34,8 \mathrm{a}$ & $36,5 \mathrm{ab}$ & $77,5 \mathrm{ab}$ & $62,0 \mathrm{~b}$ \\
\hline Glifosato & 31 & 1,44 & $32,8 \mathrm{a}$ & $39,5 \mathrm{ab}$ & $78,5 \mathrm{ab}$ & $63,0 \mathrm{~b}$ \\
\hline Glifosato & 22 e 42 & 0,72 e 0,48 & $34,5 \mathrm{a}$ & $40,0 \mathrm{ab}$ & $78,5 \mathrm{ab}$ & $60,5 \mathrm{~b}$ \\
\hline Glifosato & 22 e 42 & 0,96 e 0,72 & $34,3 \mathrm{a}$ & $38,3 \mathrm{ab}$ & $77,0 \mathrm{~b}$ & $70,5 \mathrm{ab}$ \\
\hline Chlorimuron-ethyl+lactofen & 31 & $0,01+0,072$ & $33,3 \mathrm{a}$ & $41,3 \mathrm{ab}$ & $79,5 \mathrm{ab}$ & $68,8 \mathrm{ab}$ \\
\hline Testemunha capinada & - & - & $35,5 \mathrm{a}$ & $38,8 \mathrm{ab}$ & $72,5 \mathrm{~b}$ & $61,3 \mathrm{~b}$ \\
\hline Testemunha & - & - & $34,3 \mathrm{a}$ & $42,5 \mathrm{a}$ & $88,5 \mathrm{a}$ & $81,3 \mathrm{a}$ \\
\hline F tratamentos & & & $6,07^{*}$ & $6,00 *$ & $11,1 *$ & $14,8^{*}$ \\
\hline C.V. (\%) & & & 2,77 & 2,74 & 5,07 & 6,74 \\
\hline
\end{tabular}

Médias seguidas de mesma letra na coluna não diferem significativamente entre si pelo teste Tukey a $10 \%$ de probabilidade. 
Tabela 8. Efeito de doses de glifosato, aplicada em pós-emergência, na produção de grãos de soja transgênica aos 114 DAA (dias após a aplicação). Rondonópolis, MT, $1998 / 99$.

Tratamentos

\begin{tabular}{lccc}
\hline Produtos & Época aplicação (DAA) & Dose (kg/ha) & sacas/ha \\
\hline Glifosato & 31 & 0,48 & $69,5 \mathrm{a}$ \\
Glifosato & 31 & 0,72 & $59,0 \mathrm{ab}$ \\
Glifosato & 31 & 0,96 & $57,0 \mathrm{ab}$ \\
Glifosato & 31 & 1,20 & $48,0 \mathrm{ab}$ \\
Glifosato & 31 & 1,44 & $56,5 \mathrm{ab}$ \\
Glifosato & $22 \mathrm{e} 42$ & $0,72 \mathrm{e} 0,48$ & $53,8 \mathrm{ab}$ \\
Glifosato & $22 \mathrm{e} 42$ & $0,96 \mathrm{e} 0,72$ & $57,5 \mathrm{ab}$ \\
Chlorimuron-ethyl + lactofen & 31 & $0,01+0,072$ & $53,8 \mathrm{ab}$ \\
Testemunha capinada & - & - & $54,5 \mathrm{ab}$ \\
Testemunha & - & - & $33,5 \mathrm{~b}$ \\
\hline F tratamentos & & & $28,13^{*}$ \\
C.V. (\%) & & & 12,84 \\
\hline
\end{tabular}

Médias seguidas de mesma letra na vertical não diferem significativamente entre si pelo teste Tukey a $10 \%$ de probabilidade.

* significativo a $10 \%$ de probabilidade 